\title{
The genomic organization and expression pattern of the low-affinity Fc gamma receptors (FcyR) in the Göttingen minipig
}

\author{
Jerome Egli ${ }^{1} \cdot$ Roland Schmucki $^{1}$ - Benjamin Loos ${ }^{1}$ - Stephan Reichl ${ }^{1} \cdot$ Nils Grabole $^{1}$ • Andreas Roller ${ }^{1}$. \\ Martin Ebeling ${ }^{1} \cdot$ Alex Odermatt $^{2} \cdot$ Antonio Iglesias $^{1}$
}

Received: 9 August 2018 / Accepted: 24 November 2018 / Published online: 18 December 2018

(C) The Author(s) 2018

\begin{abstract}
Safety and efficacy of therapeutic antibodies are often dependent on their interaction with Fc receptors for IgG (Fc $\gamma \mathrm{Rs})$. The Göttingen minipig represents a valuable species for biomedical research but its use in preclinical studies with therapeutic antibodies is hampered by the lack of knowledge about the porcine Fc $\gamma$ Rs. Genome analysis and sequencing now enabled the localization of the previously described Fc $\gamma$ RIIIa in the orthologous location to human FCGR3A. In addition, we identified nearby the gene coding for the hitherto undescribed putative porcine Fc $\gamma$ RIIa. The 1'241 bp long FCGR2A cDNA translates to a 274aa transmembrane protein containing an extracellular region with high similarity to human and cattle Fc $\gamma$ RIIa. Like in cattle, the intracellular part does not contain an immunoreceptor tyrosine-based activation motif (ITAM) as in human Fc $\gamma$ RIIa. Flow cytometry of the whole blood and single-cell RNA sequencing of peripheral blood mononuclear cells (PBMCs) of Göttingen minipigs revealed the expression profile of all porcine Fc $\gamma$ Rs which is compared to human and mouse. The new Fc $\gamma$ RIIa is mainly expressed on platelets making the minipig a good model to study IgG-mediated platelet activation and aggregation. In contrast to humans, minipig blood monocytes were found to express inhibitory Fc $\gamma$ RIIb that could lead to the underestimation of Fc $\gamma$ R-mediated effects of monocytes observed in minipig studies with therapeutic antibodies.
\end{abstract}

Keywords CD32 $\cdot$ Fc $\gamma$ RIIa $\cdot$ FCGR locus $\cdot$ Flow cytometry $\cdot$ Single-cell RNA sequencing $\cdot$ Sus scrofa

\section{Introduction}

Therapeutic antibodies of the $\mathrm{IgG}$ (immunoglobulin $\mathrm{G}$ ) isotype represent an important group of new medical entities and interactions of $\mathrm{Fc}$ gamma receptors (Fc $\gamma \mathrm{Rs}$ ) with the $\mathrm{Fc}$ part of IgG antibodies are crucial in the antibody-based immunotherapy. Most mammals were shown to have three functionally distinct classes of $\mathrm{Fc} \gamma \mathrm{Rs}$ with different affinities and properties. Fc $\gamma$ RIa (CD64) is capable of binding to free $\operatorname{IgG}$ antibodies and is hence considered as a high-affinity receptor.

Electronic supplementary material The online version of this article (https://doi.org/10.1007/s00251-018-01099-1) contains supplementary material, which is available to authorized users.

Antonio Iglesias

antonio.iglesias@roche.com

1 Pharma Research and Early Development (pRED), Pharmaceutical Sciences, Roche Innovation Center, Basel, Switzerland

2 Division of Molecular and Systems Toxicology, Department of Pharmaceutical Sciences, University of Basel, Basel, Switzerland
Its expression and function are conserved in most mammalian species, including pigs (Akula et al. 2014; van der Poel et al. 2011). Low-affinity receptors efficiently bind immune complexes and are divided into inhibitory and activating Fc $\gamma$ Rs. The structure and function of Fc $\gamma$ RIIb (CD32b), the inhibitory low-affinity receptor, is also highly conserved in humans, pigs, mice, and other mammalian species (Akula et al. 2014). Fc $\gamma$ RIIIa (CD16a) is an activating low-affinity $\mathrm{Fc} \gamma \mathrm{R}$ that requires the association with $\mathrm{FcR} \gamma$-chain ( $\mathrm{Fc}$ receptor common gamma chain) for signaling (Kim et al. 2003). Different affinities to IgG were observed for the human Fc $\gamma$ RIIIa V158F polymorphism within the extracellular domain (ECD). It was shown to be associated with differential response to therapeutic antibodies and disease progression (Mellor et al. 2013). Although Fc $\gamma$ RIIIa is the most widely analyzed Fc receptor in pigs (Halloran et al. 1994), its gene structure and genetic localization has not yet been determined. In mouse, the orthologous receptor of Fc $\gamma$ RIIIa is known as Fc $\gamma$ RIV (Nimmerjahn and Ravetch 2006). Fc $\gamma$ RIIa (CD32a) is another activating low-affinity receptor present in humans, non-human primates (NHPs), cattle, and rat and named as 
Fc $\gamma$ RIII in mouse (Lux and Nimmerjahn 2013). In humans, Fc $\gamma$ RIIa is expressed on the cell surface of monocytes, neutrophils, macrophages, eosinophils, basophils, dendritic cells, and platelets. It is involved in the process of phagocytosis, antibody-dependent cellular cytotoxicity (ADCC), and cytokine release (Powell and Hogarth 2008). The Fc $\gamma$ RIIa R131H polymorphism is associated with severity and progression of idiopathic pulmonary fibrosis and with response to rituximab therapy (Bournazos et al. 2010; Ziakas et al. 2016). Immune complexes binding to Fc $\gamma$ RIIa on human platelets can lead to thrombus formation (Zhi et al. 2015) and ultimately to heparin-induced thrombocytopenia (Greinacher 2009). Despite its importance, the minipig Fc $\gamma$ RIIa and its gene FCGR2A could not be identified yet.

The Göttingen minipig is increasingly used as a valuable animal model for preclinical pharmacology and drug safety studies. The high similarity to humans in terms of genetics, genomics, physiology, and anatomy makes the minipig a desired alternative to NHPs (Ganderup et al. 2012). Additionally, Göttingen minipigs have a controlled health status, are easy to handle, and need less food, space, and pharmacological products compared to domestic pigs and other non-rodent species (McAnulty et al. 2011). Minipigs mainly differ from domestic pigs in their growth range and size at sexual maturity but not in anatomical structures (Swindle et al. 2012). Regarding the immune system, no major differences between pigs and minipig have been reported so far but detailed studies are lacking (Descotes et al. 2018). The use of the minipig as an adequate species for toxicity and efficacy evaluation of therapeutic antibodies requires a detailed knowledge of the $\mathrm{Fc} \gamma \mathrm{R}$ composition and their interaction with human IgGs. However, to date, the knowledge on the binding properties of porcine $\mathrm{Fc} \gamma \mathrm{R}$ to human antibodies is still scarce. In addition, the number of low-affinity Fc $\gamma$ Rs existing in the minipig and the allocation of the FCGR genes in the corresponding locus of the Göttingen minipig genome was not conclusively determined. The latest version of the Göttingen minipig genome was generated by Heckel et al. by mapping of the whole genomesequencing data on the Duroc pig genome Sus scrofa 10.2 (Heckel et al. 2015). There, FCGR2B was the only gene annotated in the low-affinity FCGR locus. Recently, the new assembly Sus scrofa 11.1 was released containing a more accurate view of the pig genome including this particular locus (Li et al. 2017).

In this paper, we describe the complete assembly of the genetic FCGR locus of the Göttingen minipig including the exact mapping of FCGR3. Additionally, we demonstrate the identification, sequence characterization, and genomic location of FCGR2A, and the expression of low- and high-affinity Fc $\gamma$ Rs in the Göttingen minipig across blood cell types.

\section{Materials and methods}

\section{FCGR locus assembly and FCGR mapping}

The Göttingen minipig genome draft generated by Heckel et al. (2015) based on Sus scrofa 10.2 was used as a reference genome. Known sequences of FCGR2B and FCGR3A were blasted (Altschul et al. 1990) against whole genome shotgunsequencing data of the Göttingen minipig (accession: AOCR01000000) and the Wuzishan minipig (accession: AJKK01000000) to identify overlapping contigs (contiguous sequences). A minimum of $95 \%$ identity over 200 base pairs was considered as sequence identity. The ends of each newly identified contig and exon sequences from known porcine FCGR genes were again blasted against the data from both minipig breeds to form longer contiguous sequences (Fig. 1). All sequences were continuously screened for potential FCGR genes by pairwise alignment (EMBOSS Water) to published porcine, human, and mouse FCGR exons.

Genomic DNA was isolated from the frozen spleen of a Göttingen minipig using the DNeasy Blood and Tissue Kit (Qiagen). PCR on genomic DNA with primers JE24/JE26 (see Fig. 1 for primer positions and Online Resource 1 for primer sequences) allowed sequencing of the gap within an intron of FCGR3A (Fig. 1) (GenBank ID: MH574548). The two remaining gaps in the putative $F C G R 2 A$ introns were amplified by nested PCR using primers JE62/JE64 followed by JE47/JE49 and JE58/JE61 followed by JE41/JE42, respectively (Fig. 1, Online Resource 1). The obtained products were cloned using the TOPO TA cloning kit and sequenced (GenBank ID: MH574549, and MH574550). All sequencing reactions were performed by Microsynth.

\section{Identification and sequencing of putative porcine FCGR2A}

Total RNA was isolated from blood cells of Göttingen minipigs and RNA integrity was determined on the Agilent 2100 Bioanalyzer System (Agilent Technologies). Then, putative FCGR2A cDNA ends were amplified in a nested PCR approach using SMARTer RACE 5'/3' kit (Clontech). Rapid amplification of cDNA ends (RACE) PCR was performed by generation of 5'- and 3'-RACE-ready cDNA and subsequent PCR reactions using SMARTer RACE 5'/3' kit (Clontech). More precisely, 5'- and 3'-RACE-ready cDNA was generated from total RNA serving as a template. In the first round of PCR, the supplied universal primer mix (UPM) was used together with primer JE5 or JE28, designed on predicted putative FCGR2A sequences. In a second round, nested UPMshort was used with primers JE4 or JE2 to generate $5^{\prime}$ or $3^{\prime}$ cDNA ends, respectively (Fig. 1, Online Resource 1). The products were analyzed on a $0.8 \%$ agarose gel and purified using the QIAquick gel extraction kit. Sanger sequencing was 


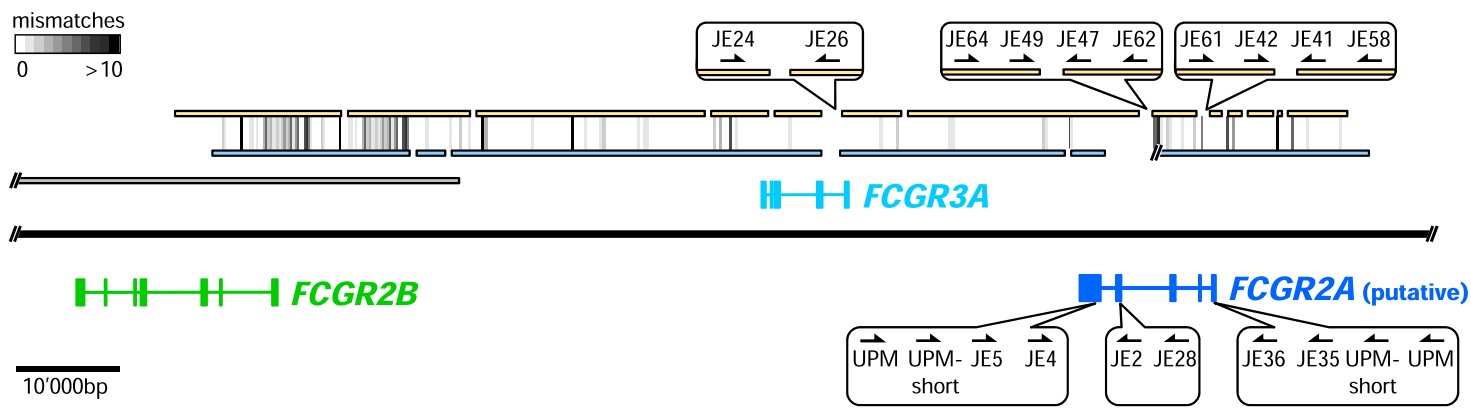

Fig. 1 Genomic organization of the minipig FCGR locus. The black line represents the genomic sequence scaled as indicated in the lower left corner. FCGR genes are shown as colored lines with boxes representing the exon structure. Genes above and below the black line are encoded at the forward strand and the reverse strand, respectively. The sequence from the initial minipig genome draft containing FCGR2B (Heckel et al. 2015) is represented by a gray line. Yellow and blue lines represent whole genome shotgun contigs of the Göttingen minipig and the

performed using several primers designed on predicted putative FCGR2A exons to identify the cDNA ends.

A final nested RT-PCR was performed on total RNA from minipig blood using first strand cDNA synthesis (New England Biolabs), the outer primers JE35/JE5, and the inner primers JE36/JE4 (Fig. 1, Online Resource 1). The product was cloned using the TOPO TA cloning kit and 30 colonies were sequenced from both sides using M13 and M13r primer. RACE PCR and RT-PCR sequences were assembled to generate the full-length transcript of the putative porcine FCGR2A.

\section{Sequence analysis and comparison}

Signal sequences were predicted by similarity to porcine FCGR2B (Qiao et al. 2006) by signalP 4.1 Server (Nielsen 2017), SMART (Letunic and Bork 2018), and Sigcleave (von Heijne 1986). SMART also predicted the extracellular structures. Transmembrane (TM) helices were predicted from similarity to human Fc $\gamma$ RIIa (Moi et al. 2010) and by the average result from the following prediction tools: TMpred (Hofmann and Stoffel 1993), DAS (Cserzo et al. 1997), SOSUI (Hirokawa et al. 1998), PredictProtein (Yachdav et al. 2014), Phobius (Kall et al. 2004), SMART, and ALOM (a program implemented at Roche according to Klein et al. (1985)).

For the phylogenetic tree, protein sequences were first aligned with MUSCLE (Edgar 2004) then poorly aligned positions and divergent regions were filtered with GBLOCKS (Castresana 2000) so that only the conserved ECD region remained. PHYLIP software package was used to calculate a protein sequence distance matrix followed by bootstrapping with 1000 replicates (Felsenstein 2005). Data was graphically displayed with the TreeExplorer software V2.12 (Jie 2017).
Wuzishan minipig, respectively. Vertical lines between the contigs of the two minipig breeds highlight regions with mismatches. The grayscale in the upper left corner indicates the number of mismatches found in intervals of $300 \mathrm{bp}$, from white ( 0 mismatches) to black (10 or more mismatches). Callouts enlarge the gaps now closed by sequencing using the primers indicated by the arrows. Refer to Online Resource 1 for primer sequences

\section{Single-cell RNA sequencing}

PBMCs were isolated using Ficoll-Paque Plus (GE Healthcare) and Leucosep tubes (Greiner bio-one, $12 \mathrm{~mL}$ ) from K2 EDTA-treated whole blood of three different healthy human donors, Göttingen minipigs, or mice. Lysis buffer (BD Pharm Lyse) was used for subsequent removal of erythrocytes. Cell count and viability were determined using the Countess Automated Cell Counter (Invitrogen).

Single-cell capture was performed using the microfluidic chromium instrument (10x Genomics) capturing single cells in microdroplets. Cell suspensions containing approximately 4000 cells per sample from three different individuals were loaded together with the provided enzyme mix, beads, and oil. According to the manufacturer's protocol, cDNA was generated, purified, and quality was checked on the Agilent 2100 Bioanalyzer System (Agilent Technologies). In a second step, a sequencing library was prepared by attaching Illumina Indices to fragmented cDNA strands. After size selection for approximately $500 \mathrm{bp}$ fragments, library concentration was measured by a Qubit fluorometer (ThermoFisher). Every sample was adjusted to a final concentration of $2.5 \mathrm{nM}$, by dilution with buffer EB (Qiagen). All samples were pooled in same amounts. A PhiX solution was added, resulting in a spike-in amount of $1 \%$ in the final pool. Pooled fragments were denatured and mixed with a master mix consisting of EPX reagents 1-3 (Illumina), resulting in a final volume of $50 \mu \mathrm{L}$ and a final concentration of $225 \mathrm{pM}$. After cluster generation, the flow cell was inserted into a HighSeq4000 instrument (Illumina). The sequencer cycle program consisted of 27 cycles for read one, 8 cycles for the index read and 99 cycles for read two.

Sequencing data were further processed using cell ranger version 2.0.0. First, fastq files were generated using the mkfastq function. Second, count files were generated using the count function. Human sequences were mapped against the genome 
assembly hg19, mouse sequences against the $\mathrm{mm} 10$, and minipig sequences against the RefSeq (reference sequence) (Pruitt et al. 2012) genome assembly Sus scrofa 11.1 containing all FCGR gene entries. Raw counts were further processed using an $\mathrm{R}$ (version 3.3.2) based in an in-house pipeline. First, data were imported using scater::read10XResults (version 1.6.3) function and QC parameters were calculated. The human raw cells were filtered using a minimum of 1.000 and a maximum of 50.000 umi (unique molecular identifier) counts in total. Second, cells having less than 300 genes expressed or more than 5\% mitochondrial gene counts were filtered out. Mouse raw counts were filtered using a minimum of 700 and a maximum of 20.000 umi counts in total and at least 200 genes expressed. Finally, minipig raw counts were filtered using a minimum of 800 and a maximum of 20.000 umi counts in total and at least 200 genes expressed. Next, data were processed using the scater::normaliseExprs function using the 99th percentile for normalization. Confounding factors were determined based on their correlation to the first ten principle components of the normalized data. For human, we identified pct_counts_top_100_endogenous_features, $\log 10$ total_features, and donor; for mouse, we identified pct_counts_top_500_features and total_counts; and for minipig, we identified pct_counts_top_50_features, $\log 10$ total_counts, and donor as independent confounding factors. We applied a linear regression model to remove the effects of the identified confounders on the normalized data. Finally, we used the Seurat:: FindClusters function (version 1.4.0.16) and Seurat::RunTSNE function to run the t-SNE (t-distributed stochastic neighbor embedding) dimensionality reduction on selected features. Clusters were summarized according to the differential expression of various genes (Online Resource 2).

\section{Flow cytometry}

Antibodies directed against porcine Fc $\gamma$ RIIa (AbD29332.1) and Fc $\gamma$ RIIa/b (AbD32591.1) were generated by Bio-Rad using the HuCAL technology. Generation and specificity of the HuCAL antibodies used here will be published elsewhere. Whole blood from three different Göttingen minipigs was collected in K2 EDTA-coated vacutainer tubes (BD). Erythrocytes were removed with the lysing buffer (BD Pharm Lyse) prior to staining of dead cells with amine-reactive dye Zombie Aqua (BioLegend). Leukocytes were then incubated in separate stainings with antibodies against porcine Fc $\gamma$ RIIa (AbD29332.1), Fc $\gamma$ RIIa/b (AbD32591.1), Fc $\gamma$ RIIIa (CD16PE, clone G7, Bio-Rad), and HuCAL Fab-A-FH-negative control antibody (AbD05930). Unlabeled HuCAL antibodies were then stained with a secondary PE-conjugated goat $\mathrm{F}(\mathrm{ab})_{2}$ fragment anti-human $\operatorname{IgG}, \mathrm{F}\left(\mathrm{ab}^{\prime}\right)_{2}$ fragment specific polyclonal antibody from Jackson ImmunoResearch. Cell events were acquired on BD LSRFortessa with BD FACSDiva and analyzed using FlowJo software.

\section{Results}

\section{Localization of porcine FCGR3A and identification of putative FCGR2A}

The low-affinity FCGR locus on chromosome 4 in the minipig genome draft based on Sus scrofa 10.2 was successfully supplemented with contigs from the Göttingen and the Wuzishan minipig and completed by PCR, cloning, and sequencing (Fig. 1, Online Resource 3). Sequences from the two minipig breeds differ in $0.31 \%$ mismatches and $1.25 \%$ indels spread over the total alignment comprising 115,000 nucleotides. The new assembly enabled the identification of exon sequences of FCGR3A in a forward orientation. Additionally, exon sequences were detected with high similarity to the porcine $F C G R 2 B$ extracellular domain (ECD) and to porcine $F C G R 3 A$ transmembrane/cytoplasmic (TM/C) region. These sequences belong to the putative porcine FCGR2A gene that is located in reverse orientation where the orthologue to human FCGR2A was expected (Fig. 1 and Fig. 4). Thus, the obtained sequence of the minipig low-affinity $F C G R$ locus is completed and entirely contiguous. The newly characterized locus is highly similar to the most recent reference sequence (RefSeq) genome assembly of Sus scrofa 11.1 (Li et al. 2017).

Exon sequences of the putative porcine FCGR2A gene were disclosed from the low-affinity FCGR locus of the minipig by alignment of the sequences to porcine, human, and mouse FCGR exons. This enabled the design of genespecific primers used for RACE PCR to identify cDNA ends. In combination with RT-PCR, we determined the complete sequence of the putative porcine FCGR2A transcript. The expected transcript, two potential polymorphisms, and three splice variants were identified in the total RNA preparation of one Göttingen minipig (Fig. 2) by Sanger sequencing of 30 clones.

The putative porcine FCGR2A cDNA is 1'241 bp long, contains an $822 \mathrm{bp}$ open reading frame (ORF) translating to a 274 amino acids (aa) long protein (RefSeq No. XM_021089520.1). Bioinformatic analysis revealed a 45 aa long signal peptide followed by an ECD region containing two immunoglobulin-like parts (Ig1, 74aa; Ig2, 78aa). Like porcine Fc $\gamma$ RIIb, the ECD contains four potential $\mathrm{N}$-glycosylation sites $\left(\mathrm{Asn}^{79}, \mathrm{Asn}^{89}, \mathrm{Asn}^{187}\right.$, and $\mathrm{Asn}^{211}$ ) identified by the common motif (N-X-S/T) (Aebi 2013). The receptor sequence predicts a 23aa hydrophobic TM part with a negatively charged aspartic acid residue allowing interaction with the FcR $\gamma$-chain (Kim et al. 2003). In the 27 aa long intracellular part, no immunoreceptor tyrosine-based activation motif (ITAM; Y-X-X-L/I) or immunoreceptor tyrosine-based inhibition motif (ITIM; S/I/V/L-X-Y-X-X-I/V/L) was found in contrast to human Fc $\gamma$ RIIa or Fc $\gamma$ RIIb, respectively (Isakov 1997; Ravetch and Lanier 2000) (Fig. 2). 
Fig. 2 The sequence of putative porcine Fc $\gamma$ RIIa mRNA is written in lower case letters with colors indicating alternating exons. In the $3^{\prime}$ untranslated region, the poly adenylation signal (aataaa) is underlined and bold. The amino acid sequence deduced from the ORF is written in capital letters below the nucleotide sequence. The predicted signal sequence is marked with a broken underline and the transmembrane (TM) spanning part is underlined. Letters in gray and italic mark the missing 24 amino acids observed in variant Fc $\gamma$ RIIal and Fc $\gamma$ RIIa3. All four potential $\mathrm{N}$-glycosylation sites $(\mathrm{N}-\mathrm{X}-\mathrm{S} / \mathrm{T})$ are circled and the negatively charged aspartic acid residue in the TM domain, required for $\mathrm{FcR}$ $\gamma$-chain interaction, is indicated as "D-" in a box acatggggagaatttgtctgtcctctggggtggaatctgtcgagccttgagagaagcctg tcttgcgctggcgctgccagaggcaacctgcgtactccaggaggtgatggggatccectc M 60

gttcctagccctccccgctgccaggagtgactgggctgattgcatgccetgccatccttt 180

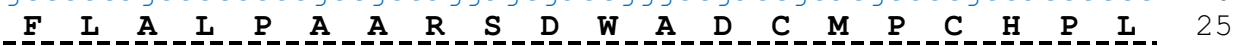

gggccacatgctcctgtggacagctctgctattcctggctcctgttcctgggacacgtgc 240 - G

agttctccaaaggctgaggtgaagcttcagcctgcatggatcaatgtgctccaggagga 300

\begin{tabular}{lllllllllllllllllllll}
$\mathbf{V}$ & $\mathbf{L}$ & $\mathbf{P}$ & $\mathbf{K}$ & $\mathbf{A}$ & $\mathbf{E}$ & $\mathbf{V}$ & $\mathbf{K}$ & $\mathbf{L}$ & $\mathbf{Q}$ & $\mathbf{P}$ & $\mathbf{A}$ & $\mathbf{W}$ & $\mathbf{I}$ & $\mathbf{N}$ & $\mathbf{V}$ & $\mathbf{L}$ & $\mathbf{Q}$ & $\mathbf{E}$ & $\mathbf{D}$ & \\
\hline
\end{tabular}

ttctgtgacactgacgtgccagggcgaccatgaccctgggaacaccaccacccagtggtt 360

$\begin{array}{llllllllllllllllllllll}\mathbf{S} & \mathrm{V} & \mathbf{T} & \mathrm{L} & \mathbf{T} & \mathbf{C} & \mathbf{Q} & \mathbf{G} & \mathbf{D} & \mathrm{H} & \mathrm{D} & \mathbf{P} & \mathbf{G} & \mathrm{N} & \mathbf{T} & \mathbf{T} & \mathbf{T} & \mathbf{Q} & \mathbf{W} & \mathbf{F} & 85\end{array}$

ccataatgggaacttcacctggaccgagaaccagcccagcttcagctttaaggccaggag 420

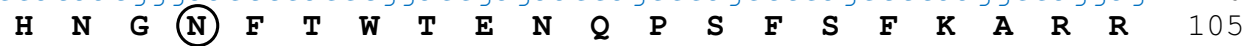

agctagcagcggatactacaggtgccagactgcctactccagtctcagcgaccctgtgca 480

$\begin{array}{lllllllllllllllllllll}\mathbf{A} & \mathbf{S} & \mathbf{S} & \mathbf{G} & \mathbf{Y} & \mathbf{Y} & \mathbf{R} & \mathbf{C} & \mathbf{Q} & \mathbf{T} & \mathbf{A} & \mathbf{Y} & \mathbf{S} & \mathbf{S} & \mathbf{L} & \mathbf{S} & \mathbf{D} & \mathbf{P} & \mathbf{V} & \mathbf{H} & 125\end{array}$

tctggatgtgatttctgactggctgctgctccagacccctagcctggtgttccaggaagg 540

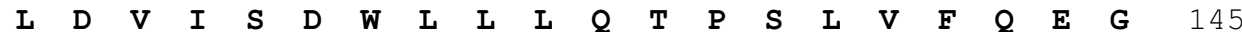

ggagcccattgtgctgaggtgccatagctggagaacaagcctctgcataaggtcgtatt 600

$\begin{array}{lllllllllllllllllllll}\mathbf{E} & \mathbf{P} & \mathbf{I} & \mathbf{V} & \mathbf{L} & \mathbf{R} & \mathbf{C} & \mathbf{H} & \mathbf{S} & \mathbf{W} & \mathbf{R} & \mathbf{N} & \mathbf{K} & \mathbf{P} & \mathbf{L} & \mathbf{H} & \mathbf{K} & \mathbf{V} & \mathbf{V} & \mathbf{F} & 165\end{array}$

tttccagaatggaaatctaagaatttcctacgtggagtccagcctctccatcccaca 660

$\begin{array}{lllllllllllllllllllll}\mathbf{F} & \mathbf{Q} & \mathbf{N} & \mathbf{G} & \mathbf{K} & \mathbf{S} & \mathbf{K} & \mathbf{K} & \mathbf{F} & \mathbf{S} & \mathbf{Y} & \mathbf{V} & \mathbf{E} & \mathbf{S} & \mathbf{S} & \mathbf{L} & \mathbf{S} & \mathbf{I} & \mathbf{P} & \mathbf{H} & 185\end{array}$

tgcaaccacagtcatagtggtgagtaccactgcacaggatcaattgggaagacgtcaca 720

$\begin{array}{lllllllllllllllllllll}\mathbf{A} & (N) & H & S & H & S & G & E & Y & H & C & T & G & S & I & G & K & T & S & H & 205\end{array}$

ctcatcacagcctgtgaacatcactgtccaaggtccggcaattctattcatctttccacc 780

$\begin{array}{llllllllllllllllllllll}S & S & Q & P & V & \text { (N) } & I & T & V & \mathcal{Q} & \mathbf{G} & \mathbf{P} & \mathbf{A} & \mathbf{I} & \mathbf{L} & \mathbf{F} & \mathbf{I} & \mathbf{F} & \mathbf{P} & \underline{\mathbf{P}} & 225\end{array}$

ttggtatcaaataacttctacctggcgatggggctccttttgcagtggatacagggct 840 \begin{tabular}{lllllllllllllllll|llll}
$\mathbf{W}$ & $\mathbf{Y}$ & $\mathbf{Q}$ & $\mathbf{I}$ & $\mathbf{T}$ & $\mathbf{F}$ & $\mathbf{Y}$ & $\mathbf{L}$ & $\mathbf{A}$ & $\mathbf{M}$ & $\mathbf{G}$ & $\mathbf{L}$ & $\mathbf{L}$ & $\mathbf{F}$ & $\mathbf{A}$ & $\mathbf{V}$ & $\mathbf{D}-$ & $\mathbf{T}$ & $\mathbf{G}$ & $\mathbf{L}$ & 245
\end{tabular}

gtattttctgtccagagagaccttcaatgctcaagggagagtggaagaacagcaagt 900 $\begin{array}{lllllllllllllllllllll}\mathbf{Y} & \mathbf{F} & \mathbf{S} & \mathrm{V} & \mathbf{Q} & \mathbf{R} & \mathbf{D} & \mathrm{L} & \mathbf{Q} & \mathbf{C} & \mathbf{S} & \mathbf{K} & \mathbf{G} & \mathbf{E} & \mathbf{W} & \mathbf{K} & \mathbf{N} & \mathbf{S} & \mathbf{K} & \mathbf{V} & 265\end{array}$

cagatggagccaaggccctcaggacaatgatcgctcattccatggtgtaacagctgtgg 960

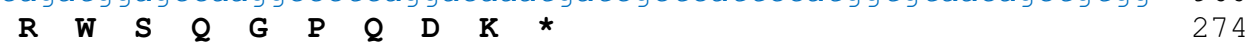

tagcagcatctcttcagtccgtaactcttcccccagccccgacttaacagcaacttgggc 1020 caaggaccctccaaggaaggaaagggcctgtgatcttcagagctaatcctaacaggtct 1080 tacctttactgatttcctgaaggccaaggtacagtcacaacccacccagctcttcaaga 1140 ctcacagcaatgtgttttcatagatgtttgacagaggctcctcaatatatgaaacctc 1200 agtaaccctgctctacttccaaataaatccaacaatctg poly(a)
The putative porcine Fc $\gamma$ RIIa.1 variant revealed a 24aa deletion within the Ig2-like part of the ECD (Gly192_Gln215del) (Fig. 2). Further variants include Fc $\gamma$ RIIa.2 lacking the whole Ig2-like part of the ECD (Asp131_Gln215del) and Fc $\gamma$ RIIa.3 lacking the whole Ig1like part of the ECD (Ala45 Ser130del) and bearing the 24aa deletion of Fc $\gamma$ RIIa.1. Furthermore, four single nucleotide polymorphisms were detected, two of them affecting the coding sequence and thus representing potential polymorphisms. The A11S polymorphism is located in the signal sequence and the H205Y polymorphism in the Ig2-like part of the ECD.

After translation of the ORF, we compared the newly identified putative porcine Fc $\gamma$ RIIa to orthologous Fc $\gamma$ Rs from different species by multiple sequence alignment (Fig. 3). All human Fc $\gamma$ RIIa orthologs share high sequence similarity 

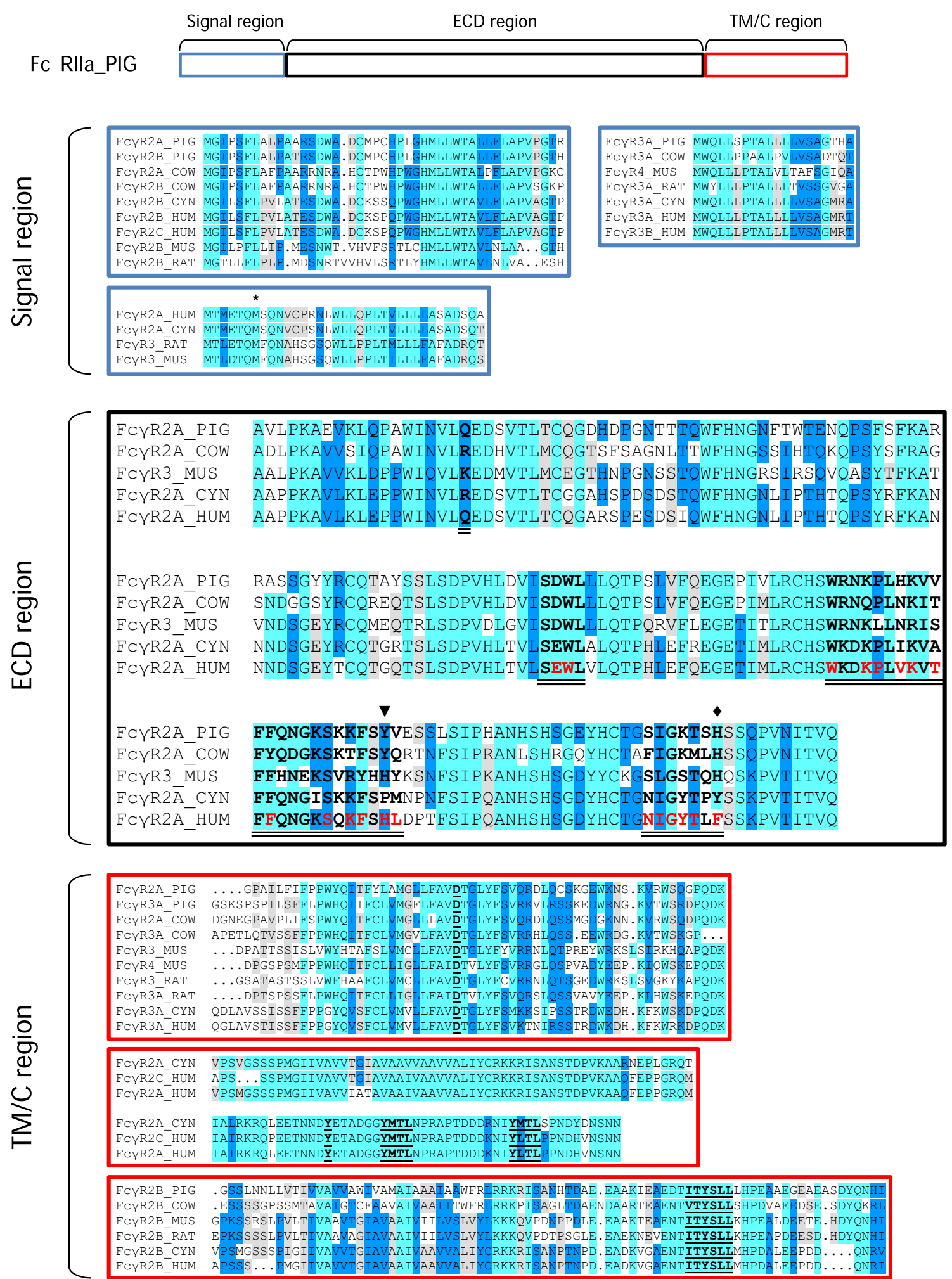

Fig. 3 Comparison of $\mathrm{Fc} \gamma \mathrm{R}$ protein sequences. A schematic representation of the putative porcine (PIG) Fc $\gamma$ RIIa transcript is shown at the top. The boxes within the transcript represent signal regions (blue boxes), extracellular domains (ECD, black box), and transmembrane/cytoplasmic regions ( $\mathrm{TM} / \mathrm{C}$, red boxes) of cattle (COW), mouse (MUS), rat (RAT), cyno (CYN), and human (HUM). Human Fc $\gamma$ RIIa amino acid residues in the ECD involved in IgG-Fc $\gamma \mathrm{R}$ contact are marked in red and deduced areas of contact are bold and double underlined. Human polymorphism R131H in Fc $\gamma$ RIIa and the minipig polymorphism $\mathrm{H} 205 \mathrm{Y}$ in Fc $\gamma$ RIIa are indicated as arrowhead and diamond, respectively. Above and below the ECD alignment are shorter alignments of the three different versions of the signal region and the TM/C regions, respectively. These alignments are enhanced with sequences from other related Fc $\gamma$ Rs to demonstrate the homology within each cluster. Note that, in the signal region, some protein sequences are annotated as starting with the methionine indicated by an asterisk. The conserved aspartic acid residue (D) for FcR $\gamma$-chain interaction, the ITAM (Y-X-X-L/I) and ITIM $(\mathrm{S} / \mathrm{I} / \mathrm{V} / \mathrm{L}-\mathrm{X}-\mathrm{Y}-\mathrm{X}-\mathrm{X}-\mathrm{I} / \mathrm{V} / \mathrm{L})$ motifs are bold and underlined 
having a conserved extracellular structure including four cysteine residues required for disulfide bonds to form Ig-like domains (black box in Fig. 3). Human Fc $\gamma$ RIIa amino acid residues involved in IgG-Fc $\gamma \mathrm{R}$ contact (Caaveiro et al. 2015) are marked in red and the deduced areas of $\operatorname{IgG}$ contact including residues predicted by other publications are indicated in bold and double underlined (Hulett et al. 1995; Radaev et al. 2001) in Fig. 3. In general, ECD regions involved in the IgG-Fc $\gamma \mathrm{R}$ interactions showed strong conservation among species, including conserved tryptophan residues, thus indicating that the identified putative porcine Fc $\gamma$ RIIa is capable of IgG binding (Fig. 3, black box). Extracellularly, the putative porcine Fc $\gamma$ RIIa (aa 46-215) shares $75 \%$ similarity to mouse Fc $\gamma$ RIII (Uniprot, P08508; aa 31-196), 79\% to cattle Fc $\gamma$ RIIa (Uniprot, A8DC37; aa 46-215), 80\% to cyno (cynomolgus monkey, Macaca fascicularis) Fc $\gamma$ RIIa (Uniprot, Q8SPW4; aa 30-199), and 79\% to human Fc $\gamma$ RIIa (Uniprot, P12318; aa 37-206). However, striking differences between the species are observed in the signal region and the $\mathrm{TM} / \mathrm{C}$ region of the $\mathrm{Fc}$ receptors. A closer inspection and comparison to other Fc $\gamma$ Rs revealed three different non-related signal regions and three different nonrelated TM/C regions (shown in Fig. 3 as blue and red boxes, respectively). These regions are well conserved between species and combined in different ways with the ECD region of Fc $\gamma$ Rs (Fig. 3). This suggests a gene "mosaicism" that is very likely the result of duplication and rearrangement of events in the complex FCGR locus. We note that this mosaicism implies that the concept of "orthology" should only be applied to the ECD region of the receptors. The intracellular ITAM of human and NHP Fc $\gamma$ RIIa is required for direct activation signaling (Isakov 1997) (Fig. 3, red middle box). Mouse Fc $\gamma$ RIII, cattle Fc $\gamma$ RIIa, and putative porcine Fc $\gamma$ RIIa, on the other hand, are lacking such an intracellular ITAM. Like human Fc $\gamma$ RIIIa, these receptors signal through associated adaptor proteins including FcR $\gamma$-chain (Lux and Nimmerjahn 2013). Charged residues in TM domains are thought to be important for protein-protein interactions in the cell membrane (Cosson et al. 1991). Especially, aspartic acid residues in TM helices are thought to be required for stable surface expression and interaction with the FcR $\gamma$-chain (Kim et al. 2003). These residues are also present in the predicted transmembrane domain of the newly identified gene, suggesting that also the putative porcine $\mathrm{Fc} \gamma \mathrm{RIIa}$ signals through the $\mathrm{FcR}$ $\gamma$-chain (Fig. 3 red upper box).

\section{A complete picture of the genomic organization of the porcine FCGR locus}

The new RefSeq assembly contains genes and curated transcripts of FCGR1A (gene ID, 613130; transcript ID, NM_001033011.1.1), FCGR2B (gene ID, 613131; transcript ID, NM_001033013.2.1), and recently also FCGR3A (gene
ID, 397684; transcript ID, NM_214391.1.1). The predicted transcript (transcript ID: XM_021089520.1) from the RefSeq gene LOC110260307 (gene ID, 110260307) codes for the 11A $205 \mathrm{H}$ polymorphism of putative porcine Fc $\gamma$ RIIa. In contrast, the transcript identified from sequences of the Göttingen and the Wuzishan minipig (Fig. 1, Online Resources 3) codes for the 11S 205Y polymorphism of putative porcine Fc $\gamma$ RIIa. However, both polymorphic variants were detected by sequencing of one Göttingen minipig.

The gene family of Fc $\gamma$ Rs displays a similar genomic organization as in most mammals (Fig. 4). Low-affinity Fc $\gamma$ Rs are organized in one locus flanked by FCRLB and FCRLA on one side, and CFAP126 and SDHC on the other side. The gene coding for the inhibitory Fc $\gamma$ RIIb is highly conserved in mammalian species. FCGR3A in humans and pigs is also known as FCGR3 in macaque and sheep and as FCGR4 in the mouse (Nimmerjahn and Ravetch 2006). Similarly, FCGR2A in humans, NHP, and cattle is referred to as Fcgr3 in the mouse (Fig. 4). The human genome was found to have species-specific duplications of the low-affinity FCGR2A and $F C G R 3 A$ and the high-affinity $F C G R 1 A$ resulting in $F C G R 2 C$ and $F C G R 3 B$ as well as pseudogenes FCGR1B and FCGR1C, respectively (Machado et al. 2012; Warmerdam et al. 1993). Human and NHP have the geneencoding high-affinity Fc $\gamma$ RIa located distant to the lowaffinity FCGR locus on chromosome 1 . The same organization was found in pig and cattle on chromosomes 4 and 3 , respectively. Dogs, mice, and rats, on the other hand, have lost the chromosomal cohesion of Fc $\gamma$ RIa and the low-affinity FCGR locus. We assume that the ECD region of the newly identified porcine $F C G R$ gene is orthologous to human $F C G R 2 A$ and mouse $F C G R 3$ due to their sequence similarities (Fig. 3) and the orientation within the FCGR locus (Fig. 4).

The phylogenetic tree shows a high intraspecies similarity between ECD region of activating Fc $\gamma$ RIIa and inhibitory Fc $\gamma$ RIIb including the orthologues in mouse and rat (Fig. 5). Fc $\gamma$ RIIIa proteins, including mouse Fc $\gamma$ RIV, form a separate group with high interspecies similarity. Full-length porcine Fc $\gamma$ RIIa, for example, shows an amino acid sequence similarity of $88 \%$ to porcine Fc $\gamma$ RIIb (Uniprot, Q461P7), and only $61 \%$ to porcine Fc $\gamma$ RIIIa (Uniprot, Q28942) whereas the ECD region of porcine Fc $\gamma$ RIIa and Fc $\gamma$ RIIb are highly similar to each other $(95.3 \%)$.

\section{Cellular distribution of FcyRs}

Understanding the functional impact of $\mathrm{Fc} \gamma \mathrm{Rs}$ requires a thorough characterization of their expression pattern in different cell types. Hereto, the expression of the different Fc $\gamma$ Rs in minipig PBMCs was addressed by single-cell RNA sequencing in comparison to human and mouse (Fig. 6). This technology was previously used to identify novel immune cell subtypes and monitor responses after immune activation (Jaitin 


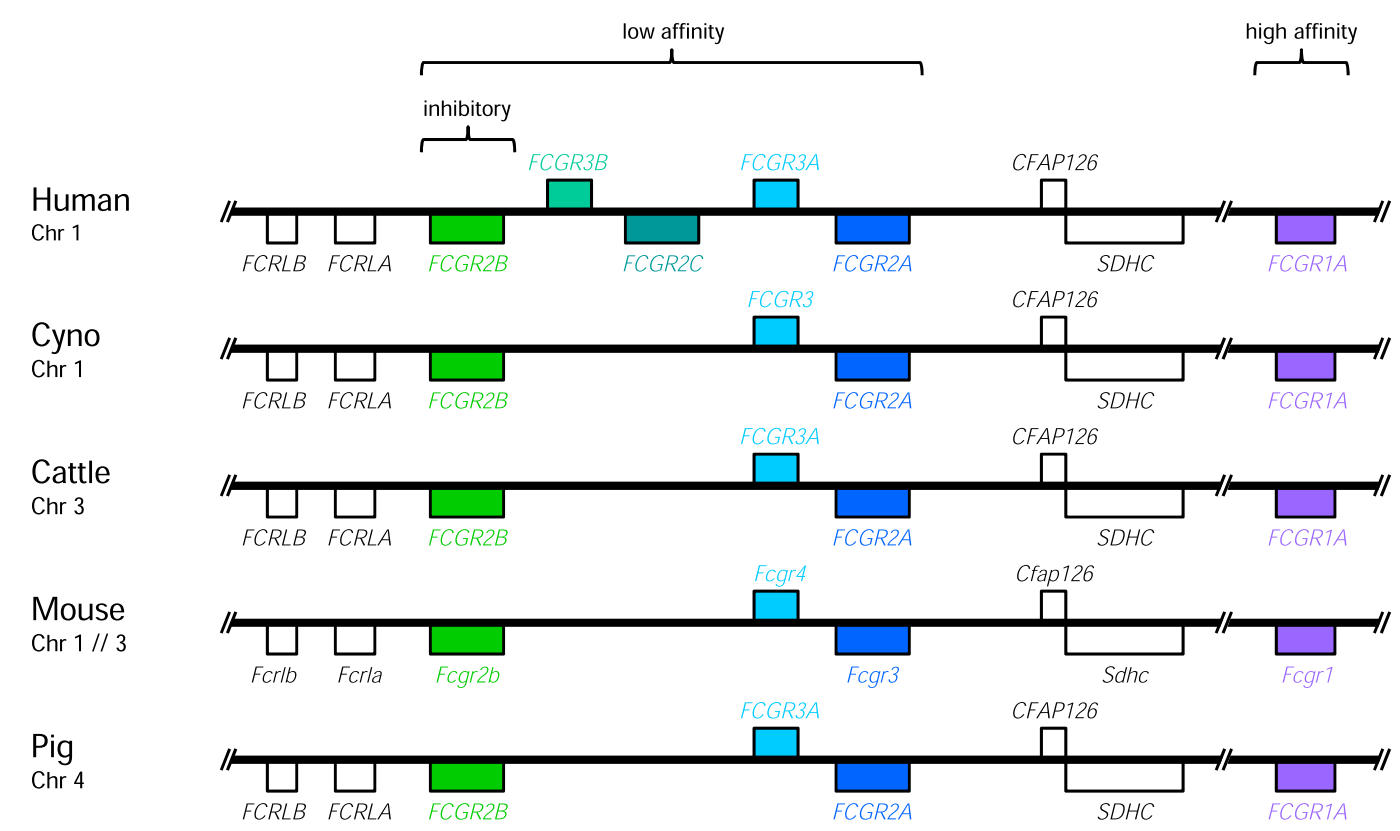

Fig. 4 Genomic organization of the FCGR locus in human, cyno, cattle, mouse, and pig according to the Ensembl database. The black lines represent a stretch of genomic DNA interrupted by lines indicating a gap of diverse length. All species shown here, except the mouse, carry the gene coding for the low-affinity receptors on the same chromosome.

et al. 2014; Villani et al. 2017); however, the cross-species comparison was not performed yet. First, cells of every species were clustered according to their expression profile and displayed by dimensionality reduction on the t-SNE plots (Fig. 6). Then, we identified clusters composed of NK cells, cytotoxic T lymphocytes, T cells, and B cells in all species by their characteristic expression profiles (Online Resource 2).
Boxes above and below the black line indicate genes oriented in forward and reverse orientation, respectively. Open boxes represent conserved genes flanking the $F C G R$ locus, whereas colored boxes represent various $F C G R$ genes found in the species indicated on the left

Such an approach enables to enumerate the expression levels of any gene of interest in all cell types in an antibodyindependent manner. It was striking to see that minipigs have a considerably larger part of PBMCs assigned to the monocytic lineage. At the same time, the number of B cells identified in minipig PBMCs is smaller than in humans and significantly smaller than in mouse PBMCs. Subsequently, the
Fig. 5 Phylogenetic tree of Fc $\gamma \mathrm{R}$ proteins in different species. Inhibitory human Fc $\gamma$ RIIb and its orthologues are colored in green, whereas low-affinity human Fc $\gamma$ RIIa and its orthologues are shown in dark blue. All human Fc $\gamma$ RIIIIa orthologues are colored in light blue. Porcine Fc $\gamma$ Rs are displayed in bold and underlined

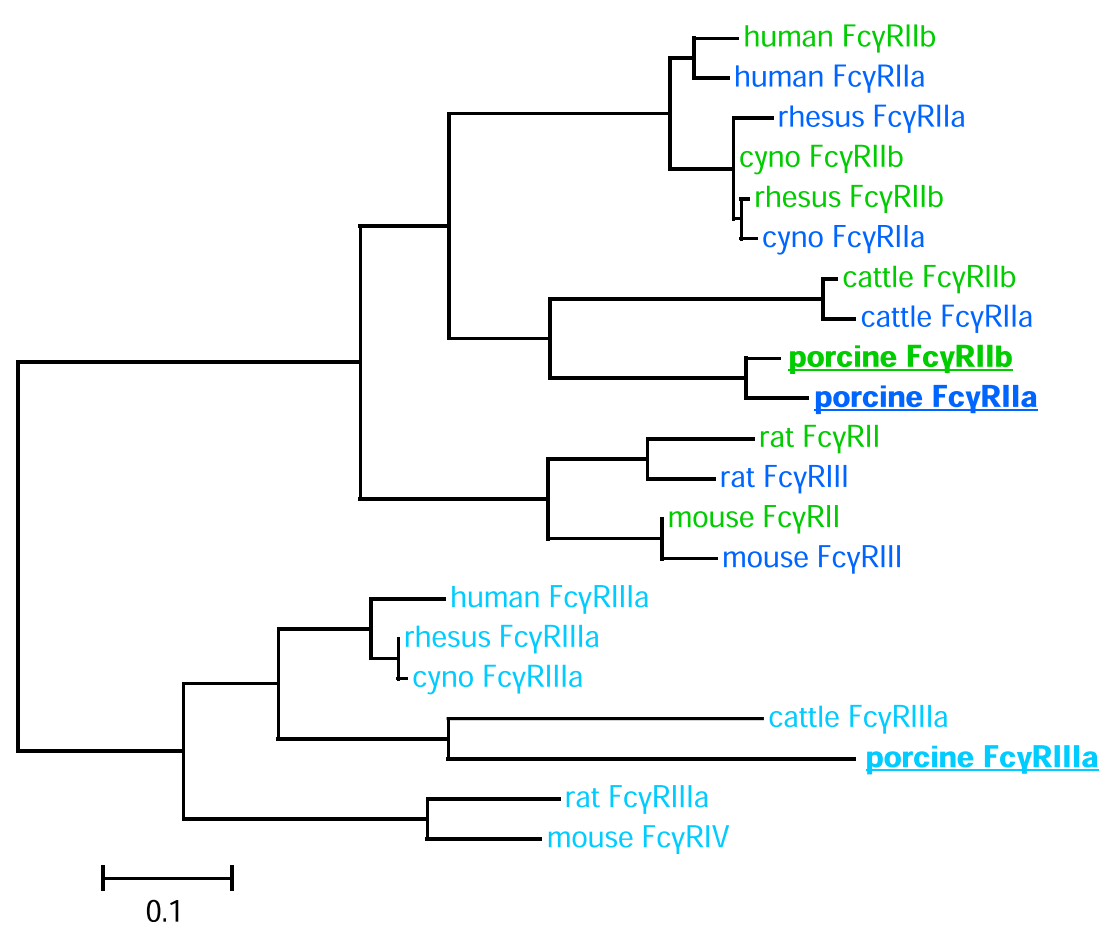




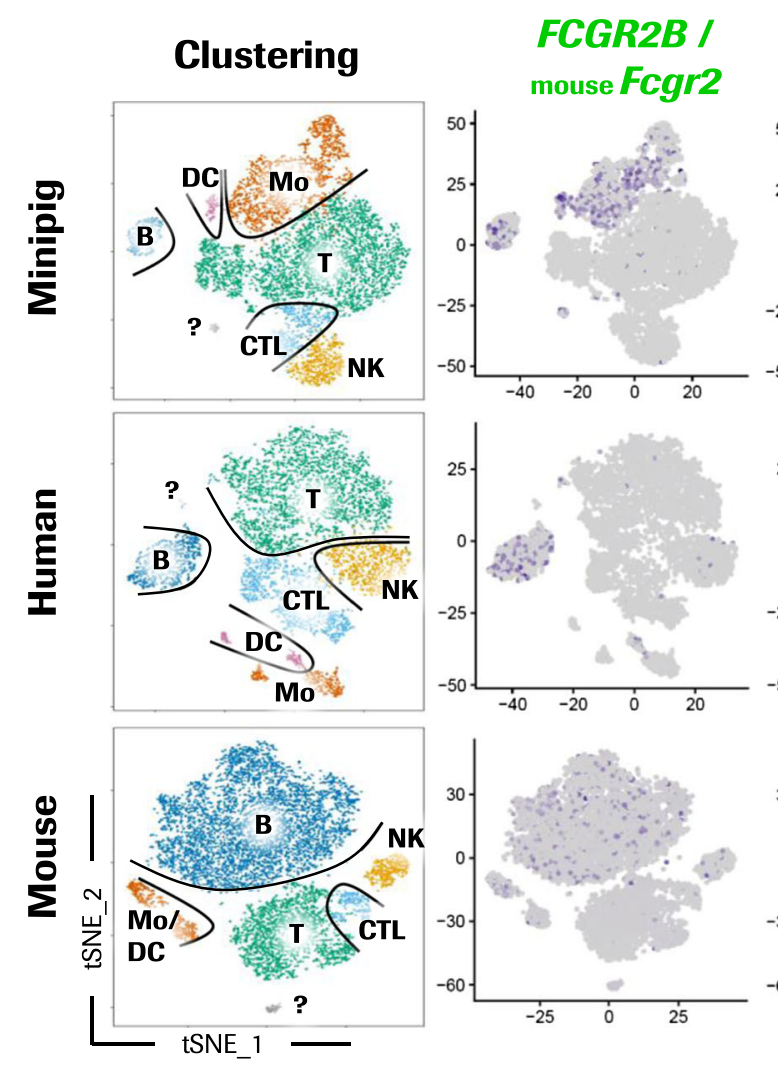

Fig. 6 Single-cell RNA sequencing analysis of FCGR expression in minipig, human, and mouse PBMCs. For every species, the cells were clustered individually according to their gene expression pattern and displayed as dot plots by dimensionality reduction using t-SNE. The clustering for every species is shown on the left with outlines for better separation. Individual clusters are labeled with "Mo" for monocytes,
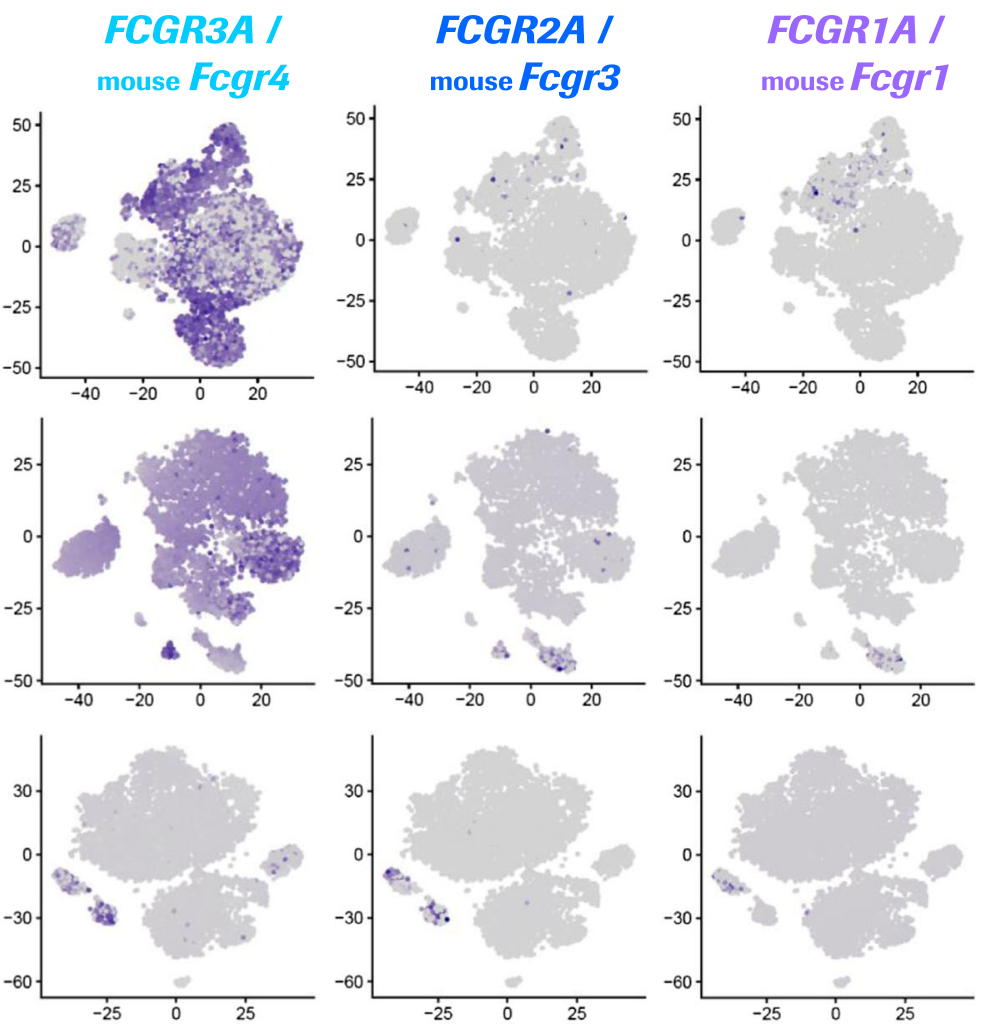

"DC" for dendritic cells, "NK" for NK cells, "CTL" for cytotoxic T lymphocytes, " $\mathrm{T}$ " for $\mathrm{T}$ cells, "B" for B cells, and "?" for mixture cell types. In mouse PBMCs, monocytes and dendritic cells are summarized in the "Mo/DC" cluster. The visualization shows the expression of the FCGR indicated above where positive cells are labeled in blue and negative cells in gray

mRNA expression of the different $\mathrm{Fc} \gamma \mathrm{Rs}$ was then analyzed in every species (Fig. 6).

The activating low-affinity Fc $\gamma$ RIIIa is most strongly expressed among the Fc $\gamma$ Rs in all the species studied here. Minipig PBMCs revealed a strong and relatively homogeneous Fc $\gamma$ RIIIa expression on all monocytes, DCs, NK cells, and cytotoxic $\mathrm{T}$ lymphocytes. Interestingly, $\mathrm{T}$ cells and $\mathrm{B}$ cells showed heterogeneous expression suggesting either different cell subsets or activation states. Human monocytes are often separated in classical, intermediate, and non-classical monocytes according to the CD14 and CD16 (Fc $\gamma$ RIIIa) expression (Ziegler-Heitbrock 2015). As expected, the larger CD14 ${ }^{\text {high }}$ classical monocyte subset did not express Fc $\gamma$ RIIIa, whereas the minor non-classical $\mathrm{CD} 14^{\text {low }}$ subset was strongly positive for Fc $\gamma$ RIIIa. Also, in mice, it is the cluster containing the monocytes that shows expression for Fc $\gamma$ RIIIa, while the other immune cell types, in contrast to the other species, show no expression. The inhibitory low-affinity Fc $\gamma$ RIIb was found to be expressed mainly on monocytes, B cells, and DCs of the minipig. Human monocytes were not found to express Fc $\gamma$ RIIb, while mouse Fc $\gamma$ RII was weaker expressed in the monocyte and DC cluster as compared to the minipig.
Expression of FcyRIIb in human and mouse PBMCs was mainly found in B cells. Fc $\gamma$ RIIa, the activating low-affinity receptor we identified with our mapping strategy, is expressed at lowest levels in minipigs and humans. In the minipig, Fc $\gamma$ RIIa mRNA was only detected in very few cells of the monocyte cluster. More monocytes were positive in the human and expression levels are slightly higher. Mouse Fc $\gamma$ RIII, the orthologue of Fc $\gamma$ RIIa, is expressed on most cells of the monocyte/DC cluster at highest levels compared to the other species. Similar expression levels and patterns were observed for Fc $\gamma$ RIa. In the minipig, the expression is at low levels and restricted to monocytes. In humans, $\mathrm{CD} 14^{\text {high }} \mathrm{CD} 16$ - classical monocytes express Fc $\gamma$ RIa, in contrast to $\mathrm{CD} 14^{\text {low }} \mathrm{CD} 16+$ non-classical monocytes. Mice show a similar Fc $\gamma$ RI expression pattern on a subset of the monocyte/DC cluster.

As gene expression studies only measure the mRNA, which may not fully reflect surface protein expression, we performed flow cytometry to assess the Fc $\gamma \mathrm{R}$ expression in the blood of three Göttingen minipigs. Cell types were identified according to the forward and side scatter properties, and their identity was confirmed using specific antibodies (Online Resource 4). Figure 7 shows a strong 
staining with the Fc $\gamma$ RIIa-specific HuCAL antibody on platelets (P1) and a weak staining on a subpopulation of eosinophils (P5). The Fc $\gamma$ RIIa/b cross-reactive HuCAL antibody stains platelets, most monocytes (P3), and some eosinophils as well. Fc $\gamma$ RIIIa staining was observed with varying intensities on monocytes, neutrophils, and eosinophils. Only a few cells were positive in lymphocyte population (P2).

\section{Discussion}

The three different classes of $\mathrm{Fc} \gamma \mathrm{Rs}$ form a finely tuned system required for efficient immune reactions in mammals. Minipigs represent a valuable alternative to NHP in preclinical studies. Thus, it is of particular importance to know all Fc $\gamma \mathrm{R}$ components in a preclinical animal model intended for testing of therapeutic antibodies. The characterization of the low- affinity $\mathrm{Fc} \gamma \mathrm{R}$ proteins and genes in minipigs should provide a basis for preclinical studies with therapeutic antibodies.

While the inhibitory receptor is widely described as Fc $\gamma$ RIIb (in the mouse known as Fc $\gamma$ RII), the nomenclature of the low-affinity-activating Fc $\gamma$ Rs has evolved in a far more divergent manner. The low-affinity Fc $\gamma$ RIIa is well-known in humans and has been described in the NHP, cattle, and other mammals, such as rabbits and sheep (Akula et al. 2014). The orthologue in the mouse, however, was named Fc $\gamma$ RIII at its discovery (Nimmerjahn and Ravetch 2006). This receptor was initially not known in pigs due to an incomplete genome characterization and therefore was not described by Akula et al. (2014). In the present study, we were able to identify the putative porcine Fc $\gamma$ RIIa located on chromosome 4 of the Göttingen minipig. The orthologue to human Fc $\gamma$ RIIIa is known in NHPs, cattle, and other mammals, including the mouse, where it was designated as Fc $\gamma$ RIV (Nimmerjahn et al. 2005). The orthologous Fc $\gamma$ RIIIa cDNA and protein were also described in the pig but the corresponding gene

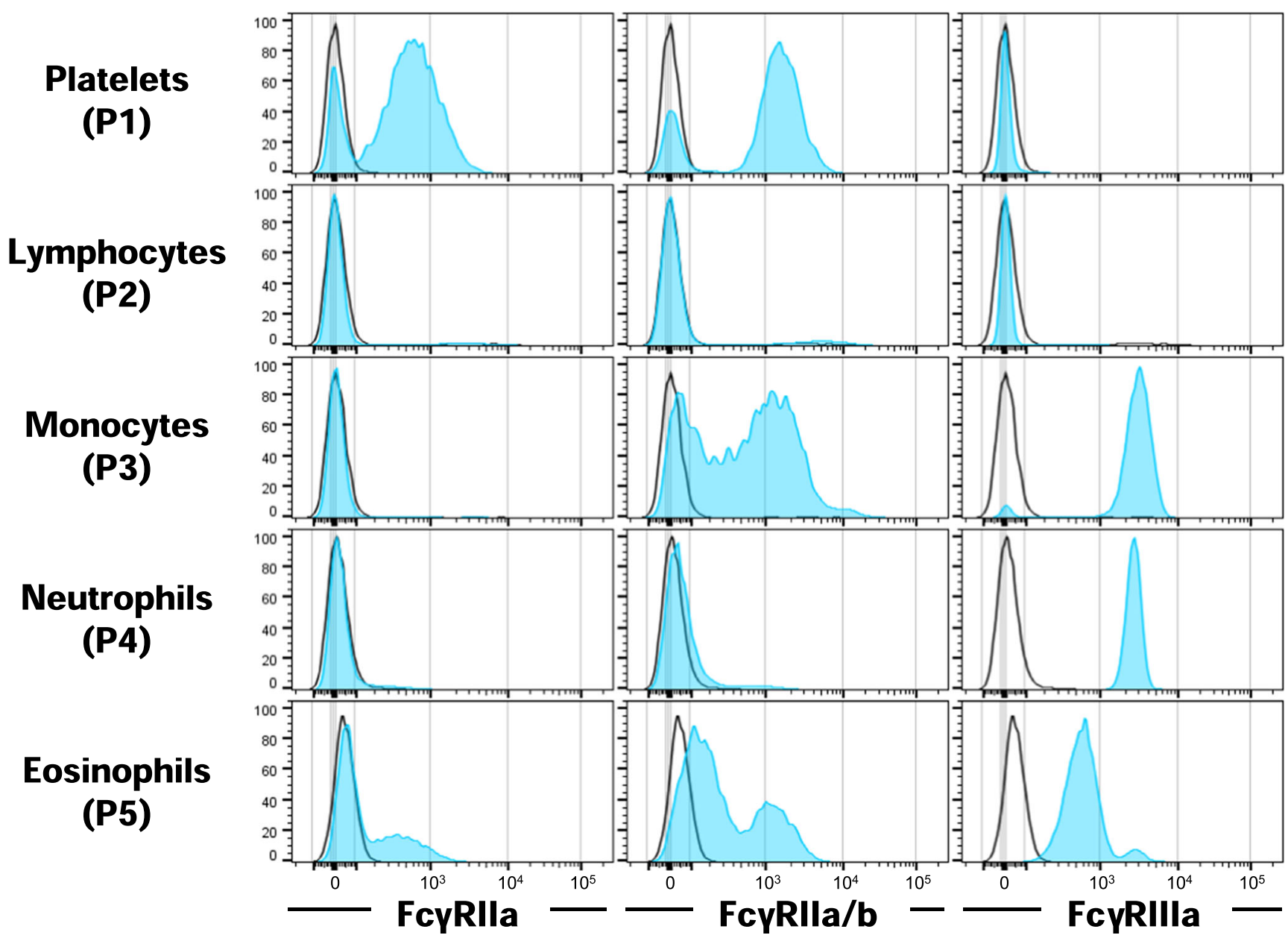

Fig. 7 Flow cytometry analysis of Fe $\gamma \mathrm{R}$ distribution on minipig blood leukocytes. Gating strategy is shown in Online Resource 4. Histograms normalized to mode show stainings observed using an Fc $\gamma$ RIIa-specific HuCAL antibody, an Fc $\gamma \mathrm{RIIa} / \mathrm{b}$ cross-reactive HuCAL antibody, and an
anti-CD16 (Fc $\gamma$ RIIIa) antibody in blue. Stainings with a HuCAL control antibody are shown as an overlay with a black line representing the background. A representative analysis of one out of three experiments with different Göttingnen minipigs is shown 
and its genomic localization was unknown (Akula et al. 2014; Halloran et al. 1994). Here, we describe the localization of the gene $F C G R 3 A$ encoding the minipig Fc $\gamma$ RIIIa between $F C G R 2 B$ and the putative FCGR2A on chromosome 4 of the Göttingen minipig on the forward strand. The identification of the putative FCGR2A and the localization of FCGR3A in pigs allow the comparison of the low-affinity FCGR locus to other species. We found that this locus of the minipig is organized similarly as in NHP, cattle, rat, and mouse with the position of the putative porcine FCGR2A gene coinciding with the other species. Nevertheless, significant differences to the human FCGR locus were observed. Thus, the complete characterization of the low-affinity FCGR locus of the minipig presented here confirms the absence of genes coding for homologs of the human Fc $\gamma$ RIIIb and Fc $\gamma$ RIIc, as is the case for all other animal species studied so far.

Sequence similarity displayed in the phylogenetic tree in Fig. 5 shows that Fc $\gamma$ RIIa and Fc $\gamma$ RIIb of the same species usually cluster together, probably originating from a duplication event early in speciation (Akula et al. 2014). The high similarity of the ECD region of porcine Fc $\gamma$ RIIb to the newly identified porcine Fc $\gamma$ RIIa fits in the pattern observed with the corresponding receptors from other species. Therefore, we suggest naming the transcript Fc $\gamma$ RIIa. However, as detailed in Fig. 3, exons coding for the signal region and the TM/C region of the Fc $\gamma$ Rs appear to be shuffled during gene duplications and rearrangements leading to a mosaic structure that is characteristic for primates, rodents, and artiodactyls, respectively. Predictions suggest intracellular signaling by porcine Fc $\gamma$ RIIa via interaction with the FcR $\gamma$ chain as it is described for cattle Fc $\gamma$ RIIa and mouse Fc $\gamma$ RIII (Lux and Nimmerjahn 2013). This similarity strengthens the hypothesis of the orthology among these receptors. On the other hand, Fc $\gamma$ RIIa in primates is known to signal via integrated intracellular ITAM. It should be considered that differences in ITAMs potentially lead to functional differences between Fc receptors (Herik et al. 1995).

Two potential polymorphisms, A11S and H205Y, were identified in the main Fo $\gamma$ RIIa transcript. The first located in the signal region and the latter was identified in the Ig2-like part of the ECD involved in the interaction with IgG antibodies (Fig. 3). Due to its location, the H205Y polymorphism could potentially influence binding affinities to certain IgG subclasses. Apart from that, we found three potential isoforms of porcine Fc $\gamma$ RIIa with unknown functions and significance, probably generated by alternative splicing. Similar splice variants were already described for porcine Fc $\gamma$ RIIb (Xia et al. 2012; Xia et al. 2011) and Fc $\gamma$ RIIIa (Jie et al. 2009). In particular, humans were shown to have splice variants and polymorphisms with significant functional consequences. Altered binding affinities are associated with the outcome of therapeutic antibody treatments and with disease progression (Bournazos et al. 2010; Ziakas et al. 2016). Studies with more minipigs are required in order to assess the potential incidence of polymorphisms, splice variants, and sub-isoforms. Additionally, their biological relevance remains to be assessed.

Biological responses triggered by Fc $\gamma$ Rs do not only depend on the affinity of IgG interaction but also on their cellular distribution (Albanesi and Daeron 2012). Knowing the expression of Fc $\gamma$ Rs on immune cells facilitates the estimation of effects triggered by IgG interaction. We performed single-cell RNA sequencing on minipig, human, and mouse PBMCs to study the Fc $\gamma R$ expression profile on various cell types.

In the Göttingen minipig, Fc $\gamma$ RIa transcripts were only identified in monocytes at similar levels as observed in human and mouse. Like in humans, no Fc $\gamma$ RIa expression was detected in minipig blood DCs although Fc $\gamma$ RIa expression was often reported in human DCs (Nimmerjahn et al. 2015; Tamoutounour et al. 2012). Fc $\gamma$ RIa expression, however, was usually analyzed in tissue resident or induced DCs and not found in blood DCs (Langlet et al. 2012). Devriendt et al. (2013) showed that the Fc $\gamma$ RIa expression profile on porcine DCs depends on the activation stimulus, and similar findings were observed for human DCs. Therefore, Fc $\gamma$ RIa expression can neither be excluded from minipig blood DCs nor from tissue-resident subsets. Varying expression levels of Fc $\gamma$ RIa between minipig and human DCs could, however, result in varying capacity for antigen presentation by immune complexes and cytokine production (Cohen-Solal et al. 2004; van der Poel et al. 2011).

Only a few monocytes of the minipig showed weak staining for Fc $\gamma$ RIIa. Generally, the Fc $\gamma$ RIIa expression in PBMCs seems to be lower in the minipig as compared to humans and mice. This low expression was also observed in porcine gene expression data from NCBI ( $\mathrm{Li}$ et al. 2017). Low expression of Fc $\gamma$ RIIa in monocytes could theoretically be upregulated upon inflammatory stimuli similar to other activating Fc receptors (Nimmerjahn et al. 2005; Pricop et al. 2001). Like humans, minipigs express Fc $\gamma$ RIIa on platelets as detected by flow cytometry (Rosenfeld et al. 1985). Platelets are mediators of immune responses upon binding of IgG immune complexes via Fc $\gamma$ RIIa. This interaction can lead to platelet activation, phagocytosis, and ultimately to thrombus formation with pathological consequences (Worth et al. 2006; Zhi et al. 2015). The minipig might thus be a good model to study platelet-mediated functions and side effects of therapeutic antibodies, such as bevacizumab-induced retinal vein thrombosis, in contrast to mice that do not express Fc $\gamma$ RIIa on platelets (Meyer et al. 2009). Gene expression data from NCBI Gene show that Fc $\gamma$ RIIa is mainly expressed in the liver and the lung of pigs. Generally, the porcine $\mathrm{Fc} \gamma \mathrm{R}$ expression is mainly detected in the liver, lung, and spleen tissue. This expression profile suggests that Fc $\gamma$ RIIa mediates important immune functions in tissue-resident cells other than platelets in the blood. 
Single-cell RNA sequencing of minipig PBMCs shows Fc $\gamma$ RIIb expression on B cells, DCs, and monocytes. Fc $\gamma$ RIIb expression on monocytes correlated with flow cytometry data using Fc $\gamma$ RIIa specific and Fc $\gamma$ RIIa/b crossreactive HuCAL antibodies. Presently, the exact cellular distribution of Fc $\gamma$ RIIb cannot be evaluated due to the lack of specific antibodies. A previous study postulates crossreactivity of anti-human CD32 antibody (AT10) without showing data (Balmelli et al. 2005), a finding that could not be confirmed in our hands (not shown). The expression of Fc $\gamma$ RIIb on minipig B cells and DCs reflects the situation in humans. On the other hand, minipig and mouse blood monocytes were found to express Fc $\gamma$ RIIb as well, whereas human blood monocytes do not (Nimmerjahn et al. 2015). Low levels of Fc $\gamma$ RIIa together with high levels of Fc $\gamma$ RIIb on minipig monocytes could result in enhanced inhibitory signaling compared to humans. Hence, this could lead to an underestimation of effects or toxicity observed in minipig studies with therapeutic antibodies with $\mathrm{Fc} \gamma \mathrm{R}$-mediated effector functions.

Porcine Fc $\gamma$ RIIIa was so far the best studied Fc receptor due to its high expression and the availability of specific antibodies. Its expression pattern was closely reflected in our single-cell RNA sequencing and flow cytometry analysis (Piriou-Guzylack and Salmon 2008). Minipig and human Fc $\gamma$ RIIIa was found to be the highest expressed Fc $\gamma \mathrm{R}$ in PBMCs. In both species, $\mathrm{T}$ cells and B cells were found to express Fc $\gamma$ RIIIa mRNA. Whereas Fc $\gamma$ RIIIa expression on human $\mathrm{T}$ cells is controversially discussed in the literature (Nimmerjahn and Ravetch 2008), it can be excluded on B cells. Therefore, the Fc $\gamma$ RIIIa expression in T cells and B cells of both species is considered as unspecific or represents different subsets or activation states. The difference between minipig and human is that Fc $\gamma$ RIIIa is only expressed on monocyte subpopulations in humans, whereas it is expressed in all monocytes in the pig (Rubic-Schneider et al. 2016). The ubiquitous expression of activating Fc $\gamma$ RIIIa on minipig monocytes could possibly counteract the inhibitory effects of Fc $\gamma$ RIIb and the low levels of Fc $\gamma$ RIIa. In therapeutic antibody research, a careful evaluation of the interaction to the various Fc $\gamma$ Rs would be needed to estimate the activation or inhibition potential of the antibody on minipig monocytes. Altogether, the human expression pattern of these Fc $\gamma$ Rs is more concordant with porcine than with murine monocytes (Fairbairn et al. 2013). The expression pattern of Fc $\gamma$ Rs is known to vary not only between species but also between individuals. As mentioned before, it can also be influenced by different stimuli, the immune status, or upon treatment. Therefore, further studies with more minipigs under different conditions are required to make a precise statement about the $\mathrm{Fc} \gamma \mathrm{R}$ distribution in health and disease.

Our work allowed the localization of Fc $\gamma$ RIIIa and the identification of the hitherto undescribed Fc $\gamma$ RIIa on chromosome 4 of the Göttingen minipig. The newly identified
Fc $\gamma$ RIIa described here is considered as an orthologue to human, NHP, and cattle Fc $\gamma$ RIIa as well as to mouse Fc $\gamma$ RIII due to the highly conserved extracellular structures. The identification of Fc $\gamma$ RIIa completes the picture of Fc $\gamma$ Rs in the pig and provides the genetic foundation for further studies. Our expression studies are the first to describe the expression of Fc $\gamma$ RIa in monocytes and Fc $\gamma$ RIIa on platelets of the Göttingen minipig. Additionally, Fc $\gamma$ RIIb was found in monocytes, DCs, and B cells. The higher expression of Fc $\gamma$ RIIIa and Fc $\gamma$ RIIb and the lacking expression of Fc $\gamma$ RIIa on monocytes are different to humans. Therefore, effects on monocytes should be carefully evaluated before using the minipig in preclinical studies with therapeutic antibodies. Nevertheless, Fc $\gamma$ RIIa expression on platelets makes the minipig a valuable model to study platelet-mediated effects of therapeutic antibodies which are hard to evaluate in mice.

Acknowledgements The authors acknowledge Roland Jenni and David Waiz for minipig handling and blood sampling, Tobias Heckel for RNA preparation, and Laetitia Petersen for assistance with flow cytometry. This work was made possible by the managerial support of Thomas Singer and Olivia Spleiss.

Open Access This article is distributed under the terms of the Creative Commons Attribution 4.0 International License (http:// creativecommons.org/licenses/by/4.0/), which permits unrestricted use, distribution, and reproduction in any medium, provided you give appropriate credit to the original author(s) and the source, provide a link to the Creative Commons license, and indicate if changes were made.

Publisher's note Springer Nature remains neutral with regard to jurisdictional claims in published maps and institutional affiliations.

\section{References}

Aebi M (2013) N-linked protein glycosylation in the ER. Biochim Biophys Acta 1833:2430-2437

Akula S, Mohammadamin S, Hellman L (2014) Fc receptors for immunoglobulins and their appearance during vertebrate evolution. PLoS One 9:e96903

Albanesi M, Daeron M (2012) The interactions of therapeutic antibodies with Fc receptors. Immunol Lett 143:20-27

Altschul SF, Gish W, Miller W, Myers EW, Lipman DJ (1990) Basic local alignment search tool. J Mol Biol 215:403-410

Balmelli C, Vincent IE, Rau H, Guzylack-Piriou L, McCullough K, Summerfield A (2005) Fc gamma RII-dependent sensitisation of natural interferon-producing cells for viral infection and interferonalpha responses. Eur J Immunol 35:2406-2415

Bournazos S, Grinfeld J, Alexander KM, Murchison JT, Wallace WA, McFarlane P, Hirani N, Simpson AJ, Dransfield I, Hart SP (2010) Association of FcgammaRIIa R131H polymorphism with idiopathic pulmonary fibrosis severity and progression. BMC Pulm Med 10:51

Caaveiro JM, Kiyoshi M, Tsumoto K (2015) Structural analysis of Fc/ FcgammaR complexes: a blueprint for antibody design. Immunol Rev 268:201-221

Castresana J (2000) Selection of conserved blocks from multiple alignments for their use in phylogenetic analysis. Mol Biol Evol 17:540 552 
Cohen-Solal JF, Cassard L, Fridman WH, Sautes-Fridman C (2004) Fc gamma receptors. Immunol Lett 92:199-205

Cosson P, Lankford SP, Bonifacino JS, Klausner RD (1991) Membrane protein association by potential intramembrane charge pairs. Nature 351:414-416

Cserzo M, Wallin E, Simon I, von Heijne G, Elofsson A (1997) Prediction of transmembrane alpha-helices in prokaryotic membrane proteins: the dense alignment surface method. Protein Eng 10:673-676

Descotes J, Allais L, Ancian P, Pedersen HD, Friry-Santini C, Iglesias A, Rubic-Schneider T, Skaggs H, Vestbjerg P (2018) Nonclinical evaluation of immunological safety in Gottingen Minipigs: the CONFIRM initiative. Regul Toxicol Pharmacol 94:271-275

Devriendt B, Goddeeris BM, Cox E (2013) The Fcgamma receptor expression profile on porcine dendritic cells depends on the nature of the stimulus. Vet Immunol Immunopathol 152:43-49

Edgar RC (2004) MUSCLE: multiple sequence alignment with high accuracy and high throughput. Nucleic Acids Res 32:1792-1797

Fairbairn L, Kapetanovic R, Beraldi D, Sester DP, Tuggle CK, Archibald AL, Hume DA (2013) Comparative analysis of monocyte subsets in the pig. J Immunol 190:6389-6396

Felsenstein J (2005) PHYLIP (phylogeny inference package) version 3.6

Ganderup NC, Harvey W, Mortensen JT, Harrouk W (2012) The minipig as nonrodent species in toxicology-where are we now? Int J Toxicol 31:507-528

Greinacher A (2009) Heparin-induced thrombocytopenia. J Thromb Haemost 7(Suppl 1):9-12

Halloran PJ, Sweeney SE, Strohmeier CM, Kim YB (1994) Molecularcloning and identification of the porcine cytolytic trigger molecule G7 as a fc-gamma-Riii-alpha (Cd16) homolog. J Immunol 153: 2631-2641

Heckel T, Schmucki R, Berrera M, Ringshandl S, Badi L, Steiner G, Ravon M, Kung E, Kuhn B, Kratochwil NA, Schmitt G, Kiialainen A, Nowaczyk C, Daff H, Khan AP, Lekolool I, Pelle R, Okoth E, Bishop R, Daubenberger C, Ebeling M, Certa U (2015) Functional analysis and transcriptional output of the Gottingen minipig genome. BMC Genomics 16:932

Herik V, Oudijk IE, TBM W, Tempelman MJ, Capel PJ, Van de Winkel JG (1995) Functional differences between two Fc receptor ITAM signaling motifs. Blood

Hirokawa T, Boon-Chieng S, Mitaku S (1998) SOSUI: classification and secondary structure prediction system for membrane proteins. Bioinformatics 14:378-379

Hofmann K, Stoffel W (1993) TMbase - a database of membrane spanning proteins segments. Biol Chem Hoppe Seyler 3874

Isakov N (1997) Immunoreceptor tyrosine-based activation motif (ITAM), a unique module linking antigen and $\mathrm{Fc}$ receptors to their signaling cascades. J Leukoc Biol 61:6-16

Jaitin DA, Kenigsberg E, Keren-Shaul H, Elefant N, Paul F, Zaretsky I, Mildner A, Cohen N, Jung S, Tanay A, Amit I (2014) Massively parallel single-cell RNA-seq for marker-free decomposition of tissues into cell types. Science 343:776-779

Jie HB, Yim D, Kim YB (2009) Porcine Fc gammaRIII isoforms are generated by alternative splicing. Mol Immunol 46:1189-1194

Jie T (2017) TreeExplorer:2.12 http://en.bio-soft.net/

Kall L, Krogh A, Sonnhammer EL (2004) A combined transmembrane topology and signal peptide prediction method. J Mol Biol 338: $1027-1036$

Kim MK, Huang ZY, Hwang PH, Jones BA, Sato N, Hunter S, Kim-Han TH, Worth RG, Indik ZK, Schreiber AD (2003) Fcgamma receptor transmembrane domains: role in cell surface expression, gamma chain interaction, and phagocytosis. Blood 101:4479-4484

Klein P, Kanehisa M, DeLisi C (1985) The detection and classification of membrane-spanning proteins. Biochim Biophys Acta 815:468-476

Langlet C, Tamoutounour S, Henri S, Luche H, Ardouin L, Gregoire C, Malissen B, Guilliams M (2012) CD64 expression distinguishes monocyte-derived and conventional dendritic cells and reveals their distinct role during intramuscular immunization. J Immunol 188: 1751-1760

Letunic I, Bork P (2018) 20 years of the SMART protein domain annotation resource. Nucleic Acids Res 46:D493-D496

Li M, Chen L, Tian S, Lin Y, Tang Q, Zhou X, Li D, Yeung CKL, Che T, Jin L, Fu Y, Ma J, Wang X, Jiang A, Lan J, Pan Q, Liu Y, Luo Z, Guo Z, Liu H, Zhu L, Shuai S, Tang G, Zhao J, Jiang Y, Bai L, Zhang S, Mai M, Li C, Wang D, Gu Y, Wang G, Lu H, Li Y, Zhu H, Li Z, Li M, Gladyshev VN, Jiang Z, Zhao S, Wang J, Li R, Li X (2017) Comprehensive variation discovery and recovery of missing sequence in the pig genome using multiple de novo assemblies. Genome Res 27:865-874

Lux A, Nimmerjahn F (2013) Of mice and men: the need for humanized mouse models to study human IgG activity in vivo. J Clin Immunol 33(Suppl 1):S4-S8

Machado LR, Hardwick RJ, Bowdrey J, Bogle H, Knowles TJ, Sironi M, Hollox EJ (2012) Evolutionary history of copy-number-variable locus for the low-affinity Fcgamma receptor: mutation rate, autoimmune disease, and the legacy of helminth infection. Am J Hum Genet 90:973-985

McAnulty PA, Dayan AD, Ganderup NC, L. HK (2011) The minipig in biomedical research

Mellor JD, Brown MP, Irving HR, Zalcberg JR, Dobrovic A (2013) A critical review of the role of Fc gamma receptor polymorphisms in the response to monoclonal antibodies in cancer. J Hematol Oncol 6:1

Meyer T, Robles-Carrillo L, Robson T, Langer F, Desai H, Davila M, Amaya M, Francis JL, Amirkhosravi A (2009) Bevacizumab immune complexes activate platelets and induce thrombosis in FCGR2A transgenic mice. J Thromb Haemost 7:171-181

Moi ML, Lim CK, Takasaki T, Kurane I (2010) Involvement of the Fc gamma receptor IIA cytoplasmic domain in antibody-dependent enhancement of dengue virus infection. J Gen Virol 91:103-111

Nielsen H (2017) Predicting secretory proteins with SignalP. Methods Mol Biol 1611:59-73

Nimmerjahn F, Bruhns P, Horiuchi K, Ravetch JV (2005) FcgammaRIV: a novel FcR with distinct IgG subclass specificity. Immunity 23:4151

Nimmerjahn F, Gordan S, Lux A (2015) FcgammaR dependent mechanisms of cytotoxic, agonistic, and neutralizing antibody activities. Trends Immunol 36:325-336

Nimmerjahn F, Ravetch JV (2006) Fcgamma receptors: old friends and new family members. Immunity $24: 19-28$

Nimmerjahn F, Ravetch JV (2008) Fcgamma receptors as regulators of immune responses. Nat Rev, Immunol

Piriou-Guzylack L, Salmon H (2008) Membrane markers of the immune cells in swine: an update. Vet Res 39:54

Powell MS, Hogarth PM (2008) Fc receptors. Adv Exp Med Biol 640: 22-34

Pricop L, Redecha P, Teillaud JL, Frey J, Fridman WH, Sautes-Fridman C, Salmon JE (2001) Differential modulation of stimulatory and inhibitory Fe gamma receptors on human monocytes by Th1 and Th2 cytokines. J Immunol 166:531-537

Pruitt KD, Tatusova T, Brown GR, Maglott DR (2012) NCBI reference sequences (RefSeq): current status, new features and genome annotation policy. Nucleic Acids Res 40:D130-D135

Qiao S, Zhang G, Xia C, Zhang H, Zhang Y, Xi J, Song H, Li X (2006) Cloning and characterization of porcine $\mathrm{Fc}$ gamma receptor II (FcgammaRII). Vet Immunol Immunopathol 114:178-184

Ravetch JV, Lanier LL (2000) Immune inhibitory receptors. Science 290: 84-89

Rosenfeld SI, Looney RJ, Leddy JP, Phipps DC, Abraham GN, Anderson CL (1985) Human-platelet Fc receptor for immunoglobulin-G identification as a 40,000-molecular-weight membrane-protein shared by monocytes. J Clin Investig 76:2317-2322 
Rubic-Schneider T, Christen B, Brees D, Kammuller M (2016) Minipigs in translational immunosafety sciences: a perspective. Toxicol Pathol 44:315-324

Swindle MM, Makin A, Herron AJ, Clubb FJJ, Frazier KS (2012) Swine as models in biomedical research and toxicology testing. Vet Pathol 49:344-356

Tamoutounour S, Henri S, Lelouard H, de Bovis B, de Haar C, van der Woude CJ, Woltman AM, Reyal Y, Bonnet D, Sichien D, Bain CC, Mowat AM, Reis e Sousa C, Poulin LF, Malissen B, Guilliams M (2012) CD64 distinguishes macrophages from dendritic cells in the gut and reveals the Th1-inducing role of mesenteric lymph node macrophages during colitis. Eur J Immunol 42:3150-3166

van der Poel CE, Spaapen RM, van de Winkel JG, Leusen JH (2011) Functional characteristics of the high affinity $\operatorname{IgG}$ receptor. FcgammaRI J Immunol 186:2699-2704

Villani AC, Satija R, Reynolds G, Sarkizova S, Shekhar K, Fletcher J, Griesbeck M, Butler A, Zheng S, Lazo S, Jardine L, Dixon D, Stephenson E, Nilsson E, Grundberg I, McDonald D, Filby A, Li W, De Jager PL, Rozenblatt-Rosen O, Lane AA, Haniffa M, Regev A, Hacohen N (2017) Single-cell RNA-seq reveals new types of human blood dendritic cells, monocytes, and progenitors. Science 356:eaah4573

von Heijne G (1986) A new method for predicting signal sequence cleavage sites. Nucleic Acids Res 14:4683-4690

Warmerdam PAM, Nabben NMJM, Vandegraaf SAR, Vandewinkel JGJ, Capel PJA (1993) The human low affinity immunoglobulin-G Fc
receptor-Iic gene is a result of an unequal crossover event. J Biol Chem 268:7346-7349

Worth RG, Chien CD, Chien P, Reilly MP, McKenzie SE, Schreiber AD (2006) Platelet FcgammaRIIA binds and internalizes IgGcontaining complexes. Exp Hematol 34:1490-1495

Xia P, Liu X, Zhang Y, Duan E, Zhang Z, Chen J, Mu C, Cui B (2012) Porcine Fc gamma RIIb sub-isoforms are generated by alternative splicing. Vet Immunol Immunopathol 145:386-394

Xia P, Liu Y, Liu X, Zhang Z, Duan E, Lu X, Zhao J, Cui B (2011) Molecular cloning and characterization of a porcine Fc gamma RIIb sub-isoform(FcgammaRIIb1). Vet Immunol Immunopathol 141:144-150

Yachdav G, Kloppmann E, Kajan L, Hecht M, Goldberg T, Hamp T, Honigschmid P, Schafferhans A, Roos M, Bernhofer M, Richter L, Ashkenazy H, Punta M, Schlessinger A, Bromberg Y, Schneider R, Vriend G, Sander C, Ben-Tal N, Rost B (2014) PredictProtein-an open resource for online prediction of protein structural and functional features. Nucleic Acids Res 42:W337-W343

Zhi H, Dai J, Liu J, Zhu J, Newman DK, Gao C, Newman PJ (2015) Platelet activation and Thrombus formation over IgG immune complexes requires integrin alphaIIbbeta3 and Lyn kinase. PLoS One 10:e0135738

Ziakas PD, Ls P, Zintzaras E (2016) FcgammaRIIa-H131R variant is associated with inferior response in diffuse large B cell lymphoma: A meta-analysis of genetic risk. J, Buon

Ziegler-Heitbrock L (2015) Blood monocytes and their subsets: established features and open questions. Front Immunol 6:423 